\title{
Incidence and Antibiotic Resistance pattern of Bacteria Associated with Wound infection in some Hospitals in Lagos, Nigeria
}

\author{
D. D. Moro ${ }^{1, *}$, H. O. Bello ${ }^{2}$ and S. O. Akano $^{3}$ \\ ${ }^{1}$ Department of Microbiology, Lagos State University \\ Apapa, Lagos, Nigeria \\ ${ }^{2}$ Department of Science Laboratory Technology, Gateway Polytechnic \\ Igbesa, Ogun State. Nigeria \\ ${ }^{3}$ Department of Medical Microbiology, Olabisi Onabanjo University \\ Sagamu, Ogun State Nigeria. \\ *Corresponding author's email: drddmoro [AT] gmail.com
}

\begin{abstract}
A total of 202 wound samples consisting of surgical, burn and accident/cut, collected randomly from patients in some hospitals in Lagos were examined using standard microbiological techniques. Wound infections were more prevalent in children and adolescent (0-20 years) with 96(48\%) as against adults (21-40) with 64(32\%) which declines from age 41-60 and above. A high incidence of bacterial isolates in wound was observed which were either pathogens or opportunistic pathogens. Pseudomonas aeruginosa, was the most frequently isolated bacterium with 128(40\%), Enterobacter sp., 60(19\%), Proteus mirabilis

56(18\%), Escherichia coli, 20(6\%) and Staphylococcus aureus, 16(5\%). Accident/cut wounds constituted 52\%, burn wounds, 32\%, while surgical wounds accounted for only 16\%. Antibiotic susceptibility studies with the disc diffusion technique on the bacterial isolates showed that most bacteria tested were resistant to amoxicillin, cotrimoxazole, nalidixic acid, augmentin, tetracycline and nitrofurantoin. However, in-vitro efficacy was shown by gentamicin and ofloxacin. Wounds independent of infection site led to

hospitalization for mostly 1-2 days (72\%) while very few were hospitalized for over 5 days (10\%).

Cleanliness and good personal hygiene should be taken seriously and enlightenment of the general public on the consequences of wound infection by our health care delivery system is strongly advocated.
\end{abstract}

Keywords--- Wound infection, surgical wound, antibiotic susceptibility, Pseudomonas aeruginosa

\section{INTRODUCTION}

Man in his struggle for survival is often involved in a battle directly or indirectly with several microbial pathogens with which he shares planet earth (1). The development of a wound infection depends on the complex interplay of many factors through which microbes such as viruses, fungi and parasites invade human body and the immune system. Therefore, if the integrity and protective function of the skin is breached, large quantities of different cell types will enter the wound and initiate inflammatory responses. Some of the characteristics of such wound infections include redness of the wound, pain, swelling and fever characterized by raised temperature (2). Examples of potential bacterial wound pathogens include Streptococcus pyogenes, Enterococcus faecalis, Staphylococcus aureus, Pseudomonas aeruginosa, Escherichia coli etc. (3).

Microbial pathogens gain access to wounds through direct contact (transfer from equipment or hands of carriers); airborne dispersal (microbes deposited from surrounding air) and self-contamination (physical migration from the patient's skin or gastrointestinal tract) (4). The development of infection is influenced largely by the virulence of the organism and immunological status of the patient. However, the presence of a microorganism within the margins of a wound does not indicate that wound infection is inevitable (5). Patients, mostly considered at risk, are those being treated with long-term steroids and those receiving chemotherapy (6). Almost all wounds, sooner or later become infected/contaminated with bacteria from the environment or a person's body. Whether they can multiply and cause infection /diseases depends on the species of bacterium, its virulence, the number of organisms introduced into the wound, the status of the host's defenses among other factors (7). 
In wound management, iodine is used in two forms i.e. cadexomer iodine, a polysaccharide starch lattice containing $0.9 \%$ elemental iodine that is released on exposure to wound exudate and povidone iodine (PVP), an iodophore composed of elemental iodine and a synthetic polymer (8). A number of dressings containing silver are being used, although silver and silver compounds have been routinely used in clinical practice for over a century (9). Other appropriate wound management interventions that can be considered to help reduce the bacterial burden particularly on the wound surface include autolytic or enzymatic debridement, surgical debridement, maggot therapy and the use topical negative pressure(TNP) in conjunction to the use of appropriate secondary dressings as required (4). This study was undertaken to study the prevalence of wound infections among different age groups and sex, isolate and characterize bacterial pathogens from wounds and to assess the antimicrobial resistance pattern of the bacterial isolates from wound infections.

\section{Sample collection:}

\section{MATERIALS AND METHODS}

A total of 202 wound samples were collected randomly from patients whose ages and sexes varied at some hospitals and health centers in the Lagos metropolis between January to December, 2008. The hospitals included Surulere General Hospital, Orthopedic Hospital, Igbobi while the clinics were Omotara Clinic and Hosanna Clinic. This study was carried out, having obtained informed consent of the subjects. All wound samples were collected with sterile cotton-tipped trans-swab stick and the swab moistened with $0.9 \%$

Sodium chloride or transport medium prior to swabbing the wound. A cotton-tipped trans-swab was then rubbed across the surface of each wound in a zigzag manner while simultaneously rotating the swab over the entire surface. The swab stick was then returned to its container in the transport medium and the swab stick broken off to allow the bottle to be replaced tightly (10). The samples were promptly taken to the laboratory within 1-2 hours for relevant biochemical analyses.

\section{Bacteriological studies:}

The swab samples were aseptically inoculated into MacConkey agar, blood agar, eosin methylene blue agar and nutrient agar plates using sterile inoculation loop and incubated aerobically at $37 \mathrm{oC}$ for $48 \mathrm{~h}$. They were then sub-cultured and pure colonies of bacteria were obtained for biochemical identification and characterization. The colonial morphology of each organism was examined and colonies were Gram stained. The organisms were identified using standard microbiological and biochemical tests (11).

\section{Antibiotic susceptibility testing.}

The antibiotic sensitivity of the isolated bacteria from wounds were determined by the disc diffusion technique. The antibiotics and their concentration in micrograms were as follows: Amoxicillin(25), cotrimoxazole(25), nitrofurantoin(30), gentamicin(10), nalidixic acid(30), ofloxacin(30), augmentin(30), tetracycline(30). E. coli (NCTC 10418) served as control. The results obtained were simply classified as resistant or sensitive on the basis of their zones of inhibition.

\section{Questionnaire:}

A set of questionnaire was designed and administered on the subjects as regards their age, sex, type of wound infection, type of treatment, site of infection and duration of hospitalization.

\section{RESULTS}

A total of 320 bacterial isolates were recovered from the 200 wound samples studied. All isolates were identified to species level with standard microbiological methods according to Barrow and Felltham, 1995. The bacterial species isolated from the wounds included Pseudomonas aeruginosa, Proteus mirabilis, Escherichia coli, Enterobacter spp, Klebsiella spp. and Staphylococcus aureus. The distribution of the bacterial isolates in the wounds were as shown in Table 1.

Table 1:Distribution of bacteria in wound.

$\begin{array}{lrc}\text { Isolate } & \text { Number } & \text { Percentage } \\ \text { Ps. aeruginosa } & 128 & 40.0 \\ \text { Enterobacter spp. } & 60 & 18.6 \\ \text { Proteus mirabilis } & 56 & 17.5 \\ \text { Klebsiella spp. } & 40 & 12.5 \\ \text { E. coli } & 20 & 6.3 \\ \text { Staphylococcus aureus } & 16 & 5.0\end{array}$


A high incidence of bacterial isolates in wound was observed in this study most of which are members of the family Enterobacreriaceae. Majority of these bacteria are pathogens or potential pathogens (Table 1). Ps. aeruginosa which is an ubiquitous pathogen was most predominant, closely followed by Enterobacter spp.(18.6\%), P .mirabilis (17.5\%) and Klebsiella spp.(12.5\%).

A study of the antibiotic resistance pattern of the bacterial isolates showed that Ps. aeruginosa showed $92.3 \%$ resistance to amoxicillin and cotrimoxazole and $85.4 \%$ resistance to nitrofurantoin and nalidixic acid, $13.0 \%$ to gentamycin and $14.2 \%$ each to both tetracycline and ofloxacin. Proteus spp. was $100 \%$ resistant to amoxicillin, cotrimoxazole, nitrofurantoin, gentamicin and nalidixic acid but was susceptible to tetracycline, augmentin and ofloxacin (Table 2).

Table 2: Antibiotic resistance pattern of bacterial isolates from wounds.

$\begin{array}{lcccccccccc}\text { Organism } & \begin{array}{c}\text { No of } \\ \text { isolates(\%) }\end{array} & \text { AMX } & \text { COT } & \text { NIT GEN } & \text { NAC } & \text { OFC } & \text { AUG } & \text { TET } \\ \text { Ps. aeruginosa } & 106 & 92.3 & 92.3 & 86.8 & 22.6 & 86.8 & 18.9 & 75.5 & 18.9 \\ \text { Proteus mirabilis } & 40 & 100 & 100 & 100 & 0 & 20 & 0 & 87.5 & 0 \\ \text { E. coli } & 18 & 100 & 66.7 & 100 & 0 & 66.7 & 66.7 & 0 & 100 \\ \text { Klebsiella spp. } & 40 & 100 & 100 & 100 & 25 & 75 & 50 & 10 & 25 \\ \text { Enterobacter spp } & 60 & 100 & 100 & 83.3 & 66.7 & 100 & 33.3 & 100 & 33.3\end{array}$

From the 202 questionnaires administered, it was observed that the most prevalent age group with wound infections was between 10-40 age range and sex appeared not to predispose people to infection (Table 3 ).

Table 3:Age and sex distribution of subjects examined

$\begin{array}{ccccc}\text { Age range } & \text { Male } & \text { Female } & \text { Total } & \text { Percentage } \\ <10 & 16 & 14 & 30 & 14.9 \\ 10-20 & 30 & 46 & 76 & 37.6 \\ 21-40 & 32 & 32 & 64 & 31.7 \\ 41-60 & 10 & 20 & 30 & 15.8 \\ >60 & 2 & - & 2 & 0.99 \\ \text { Total } & 90 & 112 & 202 & 100\end{array}$

A study of the occurrence of wound infection vis-à-vis duration of hospitalization showed that most patients (about 90) were hospitalized for between one to five days (Table 4). This means that majority of these persons were only coming as outpatients hence were likely to have recovered before the $10^{\text {th }}$ day of infection (Table 4 )

Table 4: Occurrence of infection sites and duration of hospitalization.

Infection site Duration of stay in hospital

\begin{tabular}{|c|c|c|c|c|c|c|c|}
\hline & & $1-2$ & $3-5$ & $6-9$ & $10-12$ & Total & Percentage \\
\hline Head & & 6 & - & 10 & - & 16 & 7.9 \\
\hline Hand & & 40 & 12 & 2 & - & 54 & 25.7 \\
\hline Stomach & & - & 14 & - & 2 & 16 & 7.9 \\
\hline Body & & 2 & - & - & - & 2 & 0.99 \\
\hline $84 \quad 6$ & 6 & - & & 96 & & & \\
\hline Face & & 10 & 8 & - & - & 18 & 8.9 \\
\hline Total & & 142 & 40 & 18 & 2 & 202 & \\
\hline
\end{tabular}

Leg

Most wound infections were treated by dressing while only $31 \%$ were treated with injections. This shows preference of dressing as a method of treatment of wound infection in the area studied (Table 5).

Table 5: Infections and type of treatment

$\begin{array}{lcccc}\text { Infection } & \text { Dressing } & \text { Injection } & \text { Total } & \text { Percentage } \\ \text { Surgical } & 10 & 22 & 32 & 15.8 \\ \text { Burn } & 50 & 14 & 64 & 31.7 \\ \text { Accident/cut } & 78 & 28 & 106 & 52.3 \\ \text { Total } & 138 & 74 & 202 & 100\end{array}$




\section{DISCUSSION}

Wound infection is considered one of the major health problems in the world and as an infection is one of the most frequent and severe form of complications in patients who have sustained wounds (12).

In this study, a high level of bacterial wound infection was observed and the organisms were mainly of the family Enterobacteriaceae. Gram negative bacteria were predominant with a 19:1 ratio to Gram positive bacteria. This agrees with an earlier report by Oni et al., 1997 (13). The high incidence of wound infection observed may be due simply to a wider range of infectious diseases in third world countries compared to the developed countries, including wound infections, accidents, wars and other developmental problems (1). In addition, the development of wound infection will be largely influenced by the virulence of the organisms and the immunological status of the patients. People considered mostly at risk are patients being treated with long term steroids and those receiving chemotherapy (6).

Over $50 \%$ of the wound infections were accident/cut wound which were mostly due to motor cycle accident while wounds due to burns constituted $31.7 \%$. The low level of surgical wounds in this study is likely due to high level of asepsis in the surgical wards as well as during the time of dressing changes. Wound infection is often a component of surgical wound sepsis. Surgical wound infections constituted $10 \%$ of wound infections in our environment from this study, which is consistent with the report of Ogunsola et al., 1998 (14). Pseudomonas species was the most frequently isolated pathogen accounting for $40 \%$ of cases, closely followed by Proteus species (17.5\%). The high incidence of Pseudomonas spp.in this study may be attributed to a recent outbreak of epidemic cases involving the organism. Pseudomonas aeruginosa infection in burnt patients often results in death, as the burnt area of the damaged skin are sites for bacterial infection from the environment or even the normal flora (7). Pseudomonas is especially dreaded because it often invades the bloodstream and cause chills, fever and shock. The high incidence of about $96 \%$ of the Gram negative bacterial isolates were Pseudomonas spp. Pseudomonas species thus constitutes a likely source of health hazard. Enterobacter spp., Proteus mirabilis and Klebsiella spp., almost all of which were multi-drug resistant. Nevertheless, Pseudomonas aeruginosa and Proteus mirabilis were sensitive to gentamicin, ofloxacin and tetracycline while E. coli was sensitive to gentamicin and augmentin and Klebsiella spp.to gentamicin and tetracycline. It was observed that all the Enterobacter spp. were resistant to all the antibiotics tested. It is clear from this study that majority of the bacterial isolates from wound were sensitive to gentamicin, thus underscores its significance in prescription for the treatment of Gram negative infections.

The only Gram positive isolate from this study Staphylococcus aureus was resistant to ampicillin, streptomycin, sulfonamide, tetracycline, ciproval and clindamycin but sensitive only cephalexin. Okesola et al. 1999 (15), reported that $35 \%$ of $S$. aureus isolated from infected wounds in Ibadan were methicillin resistant S. aureus (MRSA). This high prevalence of multi-drug resistant S. aureus in our environment calls for a routine testing of all $S$. aureus isolates from wound specimens for methicillin resistance. This will curb the spread of this organism and also to institute early and appropriate therapy with an ultimate reduction in the cost of management of these patients. The high level of multiple antibiotic resistances can be attributed to widespread proliferation of bacteria on which antibiotics have no effect. There is rapid spread of resistance in bacterial population, because drugs have been excessively abused and prescribed indiscriminately for trivial use (7). In addition, microbes are relentless opportunists due to their astronomical numbers and their phenomenal growth rate and adaptability, hence they can exploit new circumstances to grow and cause diseases. The gene for multiple drug resistance can as well be plasmid-borne hence studies on plasmid profile analysis of wound associated bacteria may play a very prominent role in the control and spread of drug resistance in wound-borne bacterial pathogens.

\section{REFERENCES}

1. Thompson, JD. Counter attacking major infections. Health Care vol.8 no. 2 pp.1-4, 2004.

2. Jones, J. Examining the multifactorial nature of wound infection. Wound Essentials. Vol.2. pp. 90-9, 2012.

3. Bowler, PG, Duerden, BI and Armstrong DG. Wound microbiology and associated approaches to wound management. Clin. Microbiol. Rev. vol. 14. pp 244-269, 2001.

4. Collier, M. Understanding wound inflammation. Nursing Times, vol. 99, no.25. pp. 63-64, 2003.

5. Kingsley, A. A protective approach to wound infection. .Nurs. Scand. Vol. 15 no. 30, pp. 50-58, 2001.

6. Flaganam, M. Wound infection management A.C.E. series, Edinburgh, Churchill, Livingstone, 1997.

7. Nester, C., Evan, R., Pearsal, N., Deninese, G. ,Nester, M.J. A human perspective Microbiology, Ed. McGraw-Hill Publication, New York pp. 587-589, 1998. 
8. Young T. Safe debridement in the community setting. Wound Essentials. Vol.2, pp. 82-89, 2012.

9. Cooper R. Understanding wound infection. In Cutting K, Gilchrist B, Gottrup F et al. Eds. Identifying criteria for wound infection. European Wound Management Association position document. MEP Ltd. London, 2005.

10. Donovan, S. Wound infection and wound swabbing. Prof. Nurs. Vol.12 no. 11, 1998.

11. Cheesbrough, M. Medical laboratory manual for tropical countries. Vol. II pp. 148-160, 2001.

12. Heinzamann, M., Scott M., Lam T. Factors predisposing to bacterial invasion and infection. Amer. J. Surg. Vol. 183 no.2, pp. 179-190, 2002.

13. Oni, A. A., Bakare, R.A., Okesola, A.O., Ounlowo, H.A. Pattern of bacterial pathogens in surgical wound infections. Afric. J. Med. \& Med. Sci. vol. 26: pp.136-140, 1997.

14. Ogunsola F.T., Oduyebo O., Iregbu K.C., Coker A.O., Adetunji A.. A review of nosocomial infections at LUTH: Problems and strategies for improvement. Journal of Nigerian Infection Control Association, vol.1 pp.14-20, 1998.

15. Okesola, A.O., Oni, A.A., Bakare,R.A. Prevalence and antibiotic sensitivity pattern of methicillin-resistant Staphylococcus aureus in Ibadan, Nigeria. J. Hosp. Infect. Vol.41, pp.74-76, 1999. 